\title{
Prevalence of dyspepsia: the epidemiology of overlapping symptoms
}

\author{
S.L. Grainger, H.J. Klass ${ }^{1}$, M.O. Rake ${ }^{2}$ and J.G. Williams ${ }^{3}$
}

Barking Hospital, Essex IG11 9LX, ${ }^{1}$ North Manchester General Hospital, Manchester M8 6RB,${ }^{2}$ Kent and Canterbury Hospital, Canterbury CT1 $3 N G$, and ${ }^{3}$ School of Postgraduate Studies in Medical and Health Care, Morriston Hospital, Swansea SA6 6NL, UK

Summary: Studies of the epidemiology of dyspepsia have been complicated by the use of different symptom definitions, subject populations and time frames of investigation. Published figures for the prevalence of dyspepsia vary from $20 \%$ to $40 \%$, of which perhaps only a quarter can be attributed to peptic ulcer disease. General practitioners see only a fraction of the dyspepsia within the community, the majority of which is either ignored or treated by self-medication. However, dyspepsia still accounts for about 3-4\% of all general practice consultations and for about $14 \%$ of all patients attending. In about half of all cases, even extensive investigation reveals no underlying organic lesion.

There has been much recent interest in the clinical value of grouping dyspeptic symptoms into particular subtypes. These have been called ulcer-like, dysmotility-like and reflux-like. Although these patterns have descriptive value, there is no evidence that they result from discrete pathophysiological processes. Indeed, studies both in general practice and in the community show a large degree of overlap between them.

\section{Introduction}

Epidemiology is concerned with those features that characterize and distinguish different disease entities as they appear in a population. Such investigations require agreement on what is being measured. As Knill-Jones has succinctly put it: 'It is . . . impossible to undertake proper epidemiological studies without agreed definitions of the disease in question'. ${ }^{1}$

However, there is no agreed definition for the condition known as dyspepsia. de Dombal identified no less than 20 different definitions ${ }^{2}$ and a recent Expert Committee ${ }^{3}$ listed 11 definitions of dyspepsia (including their own) which had been used over a period of nearly 25 years (Table I). Thus, Knill-Jones suggests, it is hardly surprising that epidemiologists have had particular difficulties estimating the frequency of dyspepsia in the population. Worse still 'it is not a single disease entity'. Dyspepsia is merely a description of the symptoms which may characterize many different diseases. So dyspepsia is simply 'a description, or 'label', which is applied to a large group of patients who describe their symptoms in a particular way'.

Correspondence: J.G. Williams, M.A., M.Sc., F.R.C.P. Accepted: 16 September 1993
Some estimates of dyspepsia in the population

Knill-Jones ${ }^{4}$ has also discussed the wide differences found between 40 experienced gastroenterologists and surgeons when asked to define such dyspeptic symptoms as 'nausea', 'flatulence' and 'bloating'. Careful refinement of these definitions was required before they could be utilized in a system (the Glasgow Diagnostic System for Dyspepsia or GLADYS) in which patients are interrogated about their dyspeptic symptoms by a computer. Other systems which allow more precise definitions of symptoms have also been devised, for example by de Dombal's group in Leeds. ${ }^{5}$

However, the legacy of previous differences in definition means that published population estimates of dyspepsia vary widely. Data from eight studies were collected by Knill-Jones ${ }^{1}$ (Table II). The range of prevalence figures $(19-41 \%)$ reflects not only differences in definition and in survey methods. It is also the result of differing time periods over which prevalence was measured, from 3 months to a lifetime. The estimated percentage of dyspepsia accounted for by peptic ulcer also varies widely in these series, from $13 \%$ to $56 \%$.

Earlier studies of the prevalence of dyspepsia have been well reviewed by Jones. ${ }^{6,7}$ For example, in the late 1940s Doll et al. ${ }^{8}$ collected data on over 
Table I Some definitions of dyspepsia

\begin{tabular}{|c|c|}
\hline Author (year) & Definition \\
\hline Rhind \& Watson (1968) & $\begin{array}{l}\text { Epigastric discomfort after meals, a feeling of fullness so that tight clothing is loosened, } \\
\text { eructation with temporary relief, and regurgitation of sour fluid into the mouth, with } \\
\text { heartburn ('flatulent dyspepsia') }\end{array}$ \\
\hline Crean et al. (1982) & $\begin{array}{l}\text { Any form of episodic or persistent abdominal discomfort or other symptom referable to } \\
\text { the alimentary tract, except jaundice and bleeding }\end{array}$ \\
\hline Thompson (1984) & $\begin{array}{l}\text { Chronic, recurrent, often meal-related epigastric discomfort initially suspected to be a } \\
\text { peptic ulcer }\end{array}$ \\
\hline Lagarde \& Spiro (1984) & Intermittent upper abdominal discomfort \\
\hline Talley \& Piper (1985) & $\begin{array}{l}\text { Pain, discomfort or nausea referable to the upper alimentary tract which is intermittent } \\
\text { or continuous, has been present for a month or more, is not precipitated by exertion nor } \\
\text { relieved by rest, and is not associated with jaundice, bleeding, or dysphagia }\end{array}$ \\
\hline Nyrén et al. (1987) & $\begin{array}{l}\text { Epigastric pain or discomfort a key symptom, in absence of irritable bowel symptoms } \\
\text { and organic disease ('epigastric distress syndrome') }\end{array}$ \\
\hline Talley \& Phillips (1988) & $\begin{array}{l}\text { Chronic or recurrent ( } \leqslant 3 \text { months) upper abdominal pain or nausea which may or may } \\
\text { not be related to meals }\end{array}$ \\
\hline Colin-Jones et al. (1988) & $\begin{array}{l}\text { Upper abdominal or retrosternal pain, discomfort, heartburn, nausea, vomiting, or other } \\
\text { symptoms considered to be referable to the proximal alimentary tract }\end{array}$ \\
\hline Barbara et al. (1989) & $\begin{array}{l}\text { Episodic or persistent abdominal symptoms, often related to feeding, which patients or } \\
\text { physicians believe to be due to disorders of the proximal portion of the digestive tract }\end{array}$ \\
\hline Heading (1991) & $\begin{array}{l}\text { Episodic or persistent abdominal symptoms which include abdominal pain or } \\
\text { discomfort. The term dyspepsia is not applied to patients whose symptoms are thought to } \\
\text { be arising from outside the proximal gastrointestinal tract }\end{array}$ \\
\hline Talley et al. (1991) & $\begin{array}{l}\text { Persistent or recurrent abdominal pain or abdominal discomfort centred in the upper } \\
\text { abdomen }\end{array}$ \\
\hline
\end{tabular}

From Talley et al. ${ }^{3}$, Table I, p. 46.

Table II Period prevalence of dyspepsia in different populations

\begin{tabular}{lcccc}
\hline Country & $\begin{array}{c}\text { Number in } \\
\text { sample }\end{array}$ & Dyspepsia (\%) & Peptic ulcer (\%) & $\begin{array}{c}\text { Percentage of } \\
\text { dyspepsia accounted } \\
\text { for by peptic ulcer }\end{array}$ \\
\hline England & 354 & 20 & 4 & 13 \\
England & 5,951 & 31 & 6 & 19 \\
Scotland & 1,494 & $20-23$ & 12 & 56 \\
Denmark & 1,052 & 25 & 5 & 20 \\
Sweden & 3,304 & 19 & - & - \\
England & 2,066 & 41 & 8 & 20 \\
UK & 7,428 & 41 & 8 & 42 \\
Norway & 2,027 & 24 & 10 & 24 \\
Total & 23,676 & 32 & 7.7 & \\
\hline
\end{tabular}

From Knill-Jones, ${ }^{1}$ Table I, p. 18.

6,000 employees. They concluded that about $30 \%$ of the sample had suffered from dyspepsia in the last 5 years and that about $2 \%$ had experienced a peptic ulcer. Weir and Backett ${ }^{9}$ in the late 1960 s studied some 1,500 men in a rural area of Scotland and found that one in four suffered from the 'dyspepsia-peptic ulcer syndrome', with a prevalence of ulcer disease of about $12 \%$. They concluded that dyspepsia was as common in Aberdeen as it had been in London 15 years before but that peptic ulcer was more common, with 305 ulcers per
1,000 dyspeptic cases, as opposed to Doll's figure of 178.

\section{Prevalence rates in general practice in the United Kingdom}

The prevalence of dyspepsia in general practice may be only a poor guide to its prevalence in the community as a whole. Most patients experiencing dyspeptic symptoms do not attend the doctor, 
either because they consider the symptoms too trivial or because symptoms respond to selfmedication. ${ }^{6}$ Among the first to attempt an estimate of symptom prevalence in general practice were Morrell et al. who studied over 21,000 consultations carried out by three doctors in a single general practice over the course of one year. ${ }^{10}$ Diseases of the digestive system accounted for about $8 \%$ of total consultations and $11 \%$ of new consultations initiated by the patient.

A more comprehensive one-year survey conducted by the Royal College of General Practitioners ${ }^{11}$ in the early 1980 s examined over 300,000 patients shared between 143 general practitioners (GPs). It found that the average patient consulted 4.3 times per year and that symptoms relating to the gastrointestinal tract accounted for $4.7 \%$ of total consultations and $13.6 \%$ of all patients attending. Some $71 \%$ of all gastrointestinal consultations were for dyspepsia and about 70 patients per 1,000 consulted each year because of a dyspeptic problem.

Jones $^{6}$ reports that in his general practice $4 \%$ of patients between 25 and 75 present with dyspeptic symptoms, the rate increasing with age. Thus 'a typical general practitioner may see one or two patients with dyspepsia each day'.

There is some suggestion that general practice consultations for gastrointestinal problems have declined by $30 \%$ from $1951 / 2$ to $1981 / 2{ }^{1}$ This only partly accounts for the $38 \%$ decline in peptic ulcer observed over this time. It might also result from changes in the decision to seek medical advice, bearing in mind the suggestion that at least half of all episodes of dyspepsia are treated by patients themselves. $^{6}$

\section{Prevalence of non-ulcer dyspepsia}

In half of all cases of dyspepsia, a thorough medical examination and investigation will fail to reveal the presence of any organic lesion. Grant Thompson ${ }^{12}$ examined the results of 13 separate international studies published between 1945 and 1982 and found that on average no organic lesion was detected in $46 \%$ of published cases (Table III). Considering only those studies published since 1975 reduces the figure to $34 \%$, possibly because of the greater diagnostic yield of endoscopy over $\mathrm{X}$-ray examination.

Figures published since Grant Thompson's review suggest that such 'functional' or 'non-ulcer' dyspepsia may be even more common than he suggested. Thus, Kagevi and colleagues in Sweden examined 172 consecutive dyspeptic patients in primary care and reported a rate of non-ulcer dyspepsia of $64 \% .{ }^{13}$ Capuso and co-workers in a multi-centre Italian study involving more than 1,000 dyspeptic patients found that over $70 \%$ had no organic lesion detectable on X-ray, endoscopy or ultrasonography. ${ }^{14}$ Nyrén and colleagues coined the term 'epigastric distress syndrome' to describe the condition of chronic or recurrent epigastric

Table III Proportion of dyspeptic patients with no detectable abnormalities of the upper gastrointestinal tract studied over a period of nearly 40 years

\begin{tabular}{lccc}
\hline Investigators & $\begin{array}{c}\text { Year of } \\
\text { report }\end{array}$ & $\begin{array}{c}\text { Number of } \\
\text { patients }\end{array}$ & $\begin{array}{c}\text { Percentage in } \\
\text { whom no lesion } \\
\text { was found }\end{array}$ \\
\hline Jones et al. & 1945 & 8,985 & 47 \\
Friedman & 1948 & 128 & 67 \\
Williams et al. & 1957 & 775 & 60 \\
Krag & 1965 & 430 & 30 \\
Edwards et al. & 1968 & 424 & 52 \\
Davis et al. & 1968 & 1,663 & 47 \\
Bonnevie et al. & 1971 & 114 & 26 \\
Barnes et al. & 1974 & 56 & 40 \\
Möllmann et al. & 1975 & 197 & 55 \\
Oddsson et al. & 1977 & 181 & $47 / 38 *$ \\
Horrocks et al. & 1978 & 360 & 14 \\
Beavis et al. & 1978 & 110 & 33 \\
Gear et al. & 1980 & 346 & 47 \\
Priebe et al. & 1982 & 88 & 42 \\
Mean & & & $46 \dagger$ \\
\hline
\end{tabular}

*The higher figure was obtained after roentgenography, the lower one after endoscopy; ffor the studies reported since 1975 , however, the mean is $34 \%$. From Grant Thompson, ${ }^{12}$ Table 1, p. 565. 
pain without anatomical lesions or symptoms of irritable bowel syndrome. ${ }^{15}$ They considered it to be a 'safe' diagnosis that might even represent a separate diagnostic entity.

However, these findings are not universal. Some studies have found a higher prevalence of lesions. Thus, Gear and Barnes ${ }^{16}$ completed investigation of 346 dyspeptic patients in general practice and found specific lesions in $41 \%$. The annual incidence of dyspepsia was about $1 \%$ and of demonstrable lesions was about $0.4 \%$. They accepted the original suggestion of Weir and Backett' that 'Each year those who become symptom free (either spontaneously or because of treatment) were balanced by a similar number who developed symptoms'.

Saunders, Oliver and Higson ${ }^{17}$ claimed that $70 \%$ of a general practice sample of 559 dyspeptic patients had abnormalities 'that might be considered to be consistent with acid peptic disease'. In addition, international comparisons show a wide range of variability in the prevalence of non-ulcer dyspepsia, from $19 \%$ in the USA to $76 \%$ in Denmark. ${ }^{1}$ But even the fact that two separate studies from Denmark show a range from $34 \%$ to $76 \%$ 'tells us more about methodological differences between research groups and the selection factors that operate in different populations than it enlightens us about the comparable prevalence of functional dyspepsia in different countries'. ${ }^{1}$

Thus, there is a need for well-defined questionnaires to be used in conjunction with agreed protocols for diagnostic procedures if any reliable estimates of the prevalence of dyspepsia, either 'organic' or 'functional' are to be obtained within different populations. Although patient groups in general practice or gastrointestinal outpatients may not accurately reflect the symptom pattern in the population as a whole, they do represent the most appropriate group for initial detailed investigation. They may also be of value for investigating the way dyspeptic symptoms cluster together.

\section{Prevalence of different patterns of dyspeptic symptoms}

In 1988 , a working party on dyspepsia chaired by Colin-Jones suggested that 'It is possible to divide patients with dyspeptic symptoms into a number of groups, based largely on symptoms which suggest, albeit imperfectly, causative factors' ${ }^{18}$ They proceeded to identify five different patterns of nonulcer dyspepsia, based entirely on the way in which the patient's symptoms clustered together. Of particular interest was their distinction between gastro-oesophageal or reflux-like dyspepsia, dysmotility-like dyspepsia and ulcer-like dyspepsia.

The rationale for this distinction was that these three complexes were suggestive of three different underlying pathological processes. However, this working party presented no empirical evidence to suggest that such a distinction was actually based on underlying mechanisms. Nor did two later working parties chaired by Drossman ${ }^{19}$ and Talley, ${ }^{3}$ both of which accepted these three functional categories. Indeed, Talley's group pointed out that the distinction was being made for 'descriptive purposes', and specifically that 'it needs to be shown that dividing functional dyspepsia into symptom-related sub-groups would eventually identify patients with distinct pathophysiological abnormalities or at least identify patients who will respond to specific types of management' ${ }^{3}$ Other authors have gone further. Thus, for example, Heading believes that this three-fold division of dyspeptic symptom patterns 'assists neither diagnosis in individual patients nor identification of relevant pathophysiology' ${ }^{20}$ More recently, Tucci et al. have produced some clinical findings related to $H$. pylori infection and gastric emptying which suggest 'the existence of separate subsets among dyspeptics' but even these involve a considerable degree of overlap and the authors note that 'neither the results of the present study nor the data so far available in the literature allow ... a firm conclusion' on the underlying pathogenesis. ${ }^{21}$

One of the major tasks for specialists examining the epidemiology of dyspepsia is to establish the relationship which these subcategories of functional dyspepsia bear to each other. A second question is to establish to what extent they may result from different biological mechanisms. A number of recent investigations have already addressed the first issue, and a large-scale epidemiological study in general practice has been designed to explore it further.

Knill-Jones ${ }^{1}$ reported results obtained from some 3,000 dyspeptic patients seen in general practice or as gastroenterology outpatients in both Glasgow and Holland. They were interviewed either in the traditional manner or by means of the computerized GLADYS system and symptoms characterizing dysmotility-like dyspepsia were recorded. The prevalence of these symptoms is shown in Table IV. The distribution of symptoms gives some evidence of a consistent pattern occurring among diferent patient groups. More detailed analysis showed that half of these patients were suffering from two or three symptoms simultaneously.

\section{Overlap of symptom patterns}

In a series of investigations in general practice, Jones, Lydeard and colleagues ${ }^{22-24}$ sent a validated postal questionnaire enquiring about symptoms of 'indigestion' and 'heartburn' to patients registered 
Table IV Prevalence of symptoms (\%) which characterize dysmotility-like dyspepsia in three different patient populations

\begin{tabular}{lcc}
\hline & $\begin{array}{c}\text { Computer interviews } \\
\text { Glasgow }(\mathrm{n}=2,476) \\
\text { Holland }(\mathrm{n}=654)\end{array}$ & $\begin{array}{c}\text { Forms } \\
\text { Glasgow }(\mathrm{n}=1,540)\end{array}$ \\
\hline Early repletion & 35 & 46 \\
Bloating & & \\
$\quad$ Sometimes & 31 & 24 \\
$\quad$ Often & 40 & 21 \\
Flatulence & 48 & 50 \\
Epigastric pain & 46 & 58 \\
Nausea or vomiting & 56 & 51 \\
\hline
\end{tabular}

From Knill-Jones, ${ }^{1}$ Table IV, p. 22.

Table $\mathbf{V}$ Definitions of dyspeptic symptoms used by all investigators in a large UK study of dyspepsia in general practice

\begin{tabular}{|c|c|}
\hline Localized epigastric burning or pain & $\begin{array}{l}\text { Localized pain in epigastrium frequently pinpointed by patient with } \\
\text { one finger }\end{array}$ \\
\hline Diffuse epigastric pain or burning & Poorly localized in the epigastrium; squeezing, cramping \\
\hline Heartburn & $\begin{array}{l}\text { Retrosternal burning, burning sensation behind the breastbone } \\
\text { (sternum), aggravated by lying down, stooping, large meals }\end{array}$ \\
\hline Regurgitation & Bringing up of fluid not preceded or accompanied by nausea \\
\hline Late postprandial fullness & $\begin{array}{l}\text { Feeling unduly full after a meal. Feeling 'full' an hour or more } \\
\text { after a meal }\end{array}$ \\
\hline Epigastric bloating & $\begin{array}{l}\text { Sensation of abdominal distension. Perception of increased } \\
\text { epigastric volume }\end{array}$ \\
\hline Early satiety & Not being able to complete a normal-sized meal \\
\hline Postprandial nausea & 'Sick feeling' after a meal \\
\hline Vomiting & $\begin{array}{l}\text { Bringing up of food or fluid preceded or accompanied by a sick } \\
\text { feeling (nausea) }\end{array}$ \\
\hline Fat intolerance & Discomfort in epigastrium elicited by fatty meals \\
\hline Eructation & Belching, burping \\
\hline \multirow{2}{*}{\multicolumn{2}{|c|}{$\begin{array}{l}\text { Nocturnal pain } \\
\text { Periodic discomfort or pain }\end{array}$}} \\
\hline & \\
\hline \multicolumn{2}{|l|}{ Pain relieved by food or antacids } \\
\hline
\end{tabular}

at different health centres. Their first investigation confined to two centres in Hampshire, ${ }^{22}$ involving over 2,000 patients, found that $38 \%$ had experienced dyspepsia in the past 6 months, although only one patient in four consulted their doctor over that time. Examining the overlap between upper abdominal pain and heartburn showed that $43 \%$ of patients with dyspepsia also had reflux symptoms (Figure 1).

Confident of their procedure, they extended it to five different geographical regions in Britain from Southampton to Aberdeen. The 6 month prevalence of dyspepsia reported among 7,000 respondents was $41 \%$, varying from $38 \%$ in Southampton to $53 \%$ in Glasgow. No less than $56 \%$ of patients with indigestion had also experienced heartburn. ${ }^{24}$ The authors comment specifically on previous attempts to separate these two symptom patterns, and on their own finding of "considerable overlap between reflux symptoms and epigastric pain, with many patients experiencing both of these, making a neat distinction difficult and clinical diagnosis problematical'. ${ }^{23}$

Finally, they followed up 2,460 patients 2 years after their original survey ${ }^{23}$ and found the 6 month prevalence rate unchanged at $38 \%$. The annual incidence of new cases of dyspepsia was $11.5 \%$ and of peptic ulcer was $0.5 \%$. Although $26 \%$ of patients had become symptom-free, there were $23 \%$ of new cases, giving credence to the suggestion of Gear and Barnes ${ }^{16}$ that as some dyspeptics recover, others take their place.

A very elegant exploration of dyspeptic subgroups was performed by Talley and colleagues at the Mayo Clinic in Minnesota. ${ }^{25}$ A questionnaire on dyspeptic experience was sent to community residents aged 30-64 and replies were received from 835 . The questionnaire was sufficiently 
Upper abdominal symptoms

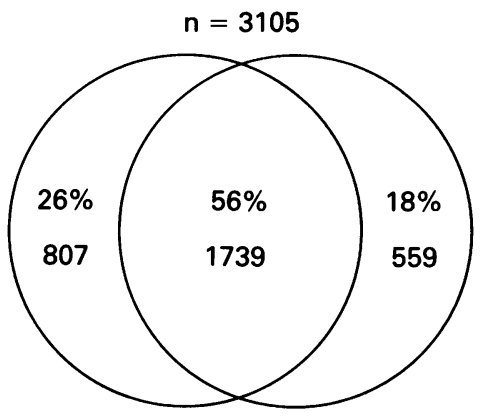

Upper abdominal symptoms

Heartburn

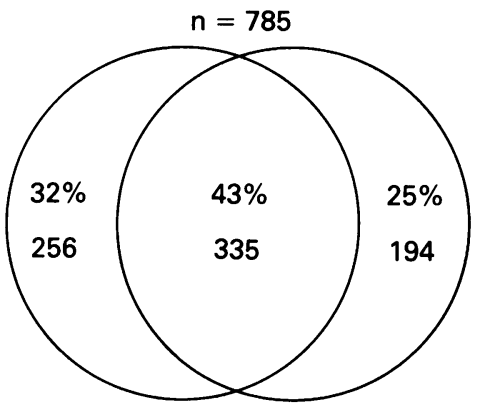

Figure 1 Distribution of upper abdominal symptoms and heartburn in two separate investigations in general practice shows an overlap between them of $43 \%$ and $56 \%$, respectively. From Jones and Lydeard, ${ }^{22}$ Figure 2, p. 31 (top) and Jones et al., ${ }^{23}$ Figure 2, p. 403 (bottom). detailed to distinguish between four categories of dyspepsia: ulcer-like, dysmotility-like, reflux-like and unspecified.

The one-year prevalence rate of dyspepsia was 26 per 100 . Of these, $64 \%$ had ulcer-like dyspepsia, $31 \%$ dysmotility-like and $38 \%$ reflux-like dyspepsia (Figure 2). However, $43 \%$ of subjects fell into more than one category. Thus, $17 \%$ had a combination of ulcer- and reflux-like dyspepsia, 10\% ulcer- and dysmotility-like, $3 \%$ reflux- and dysmotility-like, and $13 \%$ had all three categories

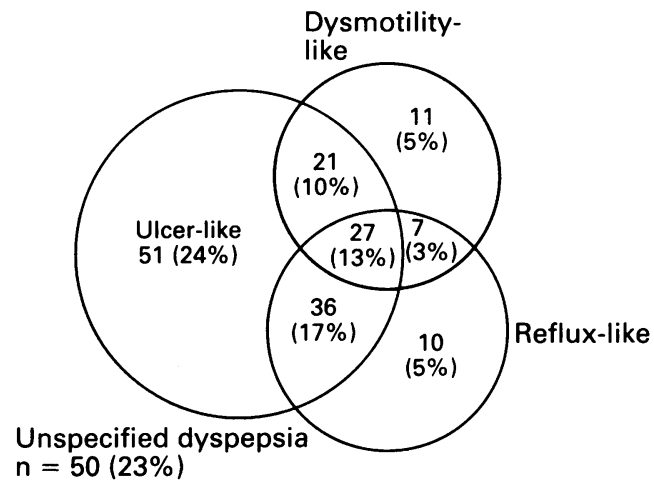

Figure 2 Inter-relationship between the dyspeptic subgroups in a community population investigated by questionnaire. Percentages refer to a total patient number, $n=213$. From Talley et al., ${ }^{25}$ Figure 2, p. 1263.

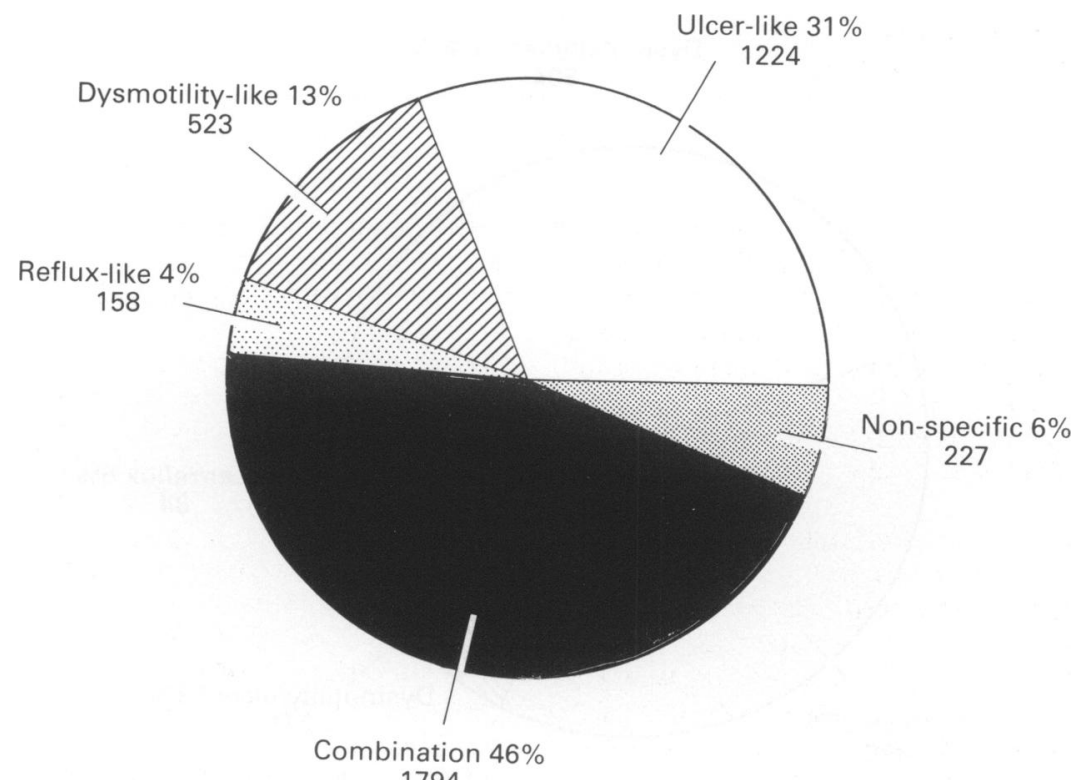

1794

Figure 3 Distribution of various patterns of dyspepsia in a general practice population of 3,926 patients in the UK. 
together. A history of peptic ulcer did not distinguish the ulcer-like from the other two categories, although individuals with frequent dyspepsia were more likely to report a history of peptic ulcer.

Reviewing their results, these authors conclude that 'Although dyspepsia is very common in the community and the majority have ulcer-like symptoms, there is such overlap among the dyspepsia groups that a classification based on symptoms alone in uninvestigated patients may not be useful'.25

\section{Answering the questions}

A large-scale study of dyspepsia in the general practice population is under way in the United Kingdom involving some 1,000 general practitioners and 10,000 dyspeptic patients from a wide range of geographical regions. The study aims to establish to what extent the various symptoms clusters in dyspepsia represent discrete categories and how far they overlap, to explore the geographical distribution of dyspeptic symptoms, and to examine the response of dyspeptic patients to treatment with the prokinetic agent cisapride. Patients' symptoms are recorded following strict, pre-defined criteria (Table V) and the results will be analysed according to symptom categories of ulcerlike, dysmotility-like, reflux-like and non-specific dyspepsia. Data from patients whose symptoms fall into more than one category will be analysed separately and this may also permit the discovery of naturally occurring symptom clusters other than the four recognized subgroups. Preliminary analysis of data on 3,926 patients is shown in Figures 3 and 4.

The treatment arm of the UK multi-centre study will permit the investigators to assess the response both of individual symptoms and of the four different symptom patterns to treatment with cisapride which enhances gastrointestinal motility without exerting any effects on other possible causes of dyspepsia, for example, acid secretion. It will be of particular interest to establish whether cisapride exerts any 'specific' effect on dyspeptic symptoms that can be related to its known biological activity. An unambiguous answer to this question, whether positive or negative, should help greatly to clarify the issue of whether dyspeptic symptom clusters possess anything other than a purely descriptive value.

\section{Conclusion: issues still unresolved}

The epidemiology of dyspepsia is still replete with problems. Some of them, for example, questions of symptom definition and sampling frames, are potentially soluble if adequate attention is directed to protocol design and selection of subjects. However, there is still much to be learned about the prevalence and incidence of those symptoms that come to consultation, let alone their frequency in the community. The limited data available suggest

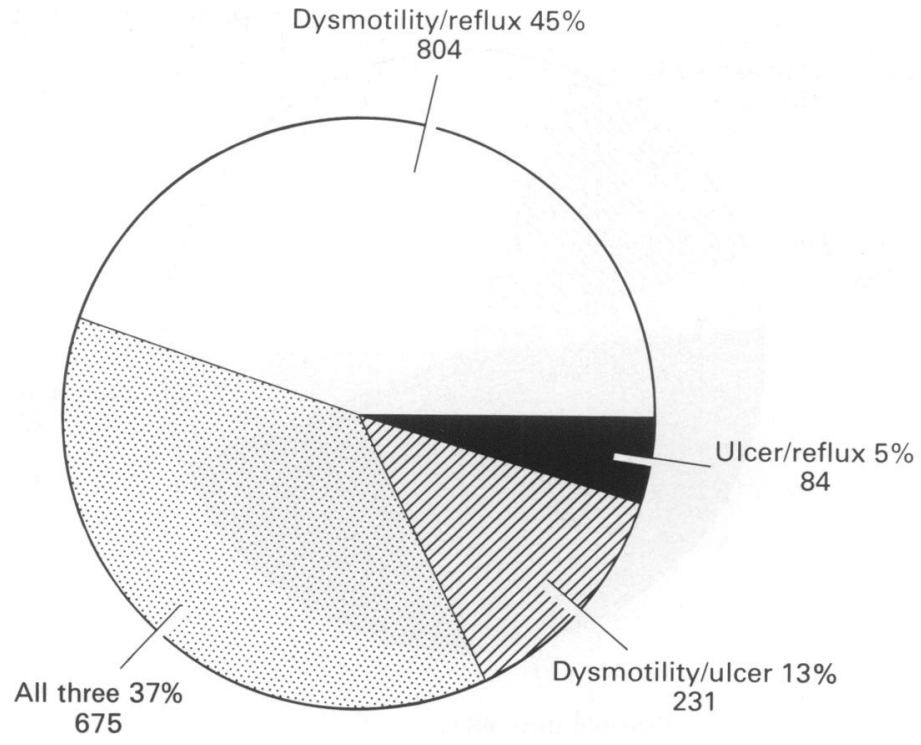

Figure 4 Combination of ulcer-like, dysmotility-like and reflux-like dyspepsia found in a general practice population of 3,926 patients in the UK. 
that patterns of dyspepsia in the community, which are often either ignored or which receive selfmedication, may be somewhat different from those seen by the physician.

A more difficult problem concerns the pattern of presenting symptoms and the extent to which it may be related to the underlying pathophysiology.
It may be of some value to distinguish between conceptual categories of dyspepsia ('for descriptive purposes $^{33}$ ). But there is little evidence as yet that they are distinguishable either on a clinical or a pathophysiological basis, or that symptom patterns give any clue as to the most appropriate form of management.

\section{References}

1. Knill-Jones, R.P. Geographical differences in the prevalence of dyspepsia. Scand J Gastroenterol 1991, 26 (Suppl 182): 17-24.

2. de Dombal, F.T. Analysis of foregut symptoms. In: Baron, J.H. \& Moody, F.G. (eds) Butterworths International Medical Reviews. Gastroenterology. Butterworths, London, 1981, pp. 49-66.

3. Talley, N.J., Colin-Jones, D., Koch, K.L., Koch, M., Nyrén, O. \& Stanghellini, V. Functional dyspepsia: a classification with guidelines for diagnosis and management. Gastroenterol Int 1991, 4: 145-160.

4. Knill-Jones, R.P. A formal approach to symptoms in dyspepsia. Clin Gastroenterol 1985, 14: 517-529.

5. Davenport, P.M., Morgan, A.G., Darnborough, A. \& de Dombal, F.T. Can preliminary screening of dyspeptic patients allow more effective use of investigational techniques? Br Med J 1985, 290: 217-220.

6. Jones, R. Self care and primary care of dyspepsia: a review. Family Prac 1987, 4: 68-77.

7. Jones, R. Dyspeptic symptoms in the community. Gut 1989 , 30: $893-898$.

8. Doll, R., Avery-Jones, F. \& Buckatzsch, M.M. Occupational factors in the aetiology of gastric and duodenal ulcers, with an estimate of their incidence in the general population. $M R C$ Special Reports Series, No. 276. HMSO, London, 1951.

9. Weir, R.D. \& Backett, E.M. Studies of the epidemiology of peptic ulcer in a rural community: prevalence and natural history of dyspepsia and peptic ulcer. Gut 1968, 9: 75-83.

10. Morrell, D.C., Gage, H.G. \& Robinson, N.A. Symptoms in general practice. J R Coll Gen Prac 1971, 21: 32-43.

11. Royal College of General Practitioners, Office of Population Censuses and Surveys, Department of Health and Social Security. Morbidity Statistics from General Practice 1981-82. Third national study. HMSO, London, 1986.

12. Grant Thompson, W. Non-ulcer-dyspepsia. Can Med Assoc J 1984, 130: $565-569$.

13. Kagevi, I., Löfstedt, S. \& Persson, L.-G. Endoscopic findings and diagnoses in unselected dyspeptic patients at a primary health-care center. Scand J Gastroenterol 1989, 24: 145-150.

14. Capurso, L., Koch, M.M., Dezi, A., Koch, G. \& DiCiocco, $\mathrm{U}$. Towards a quantitative diagnosis of dyspepsia: the value of clinical symptoms. Dyspepsia Project Report. Ital J Gastroenterol 1988, 20: 191-202.

15. Nyrén, O., Adami, H.-O., Gustavsson, S., Lindgren, P.G., Lööf, L. \& Nyberg, A. The epigastric distress syndrome. $J$ Clin Gastroenterol 1987, 9: 303-309.

16. Gear, M.W.L. \& Barnes, R.J. Endoscopic studies of dyspepsia in a general practice. Br Med J 1980, 1: 1136-1137.

17. Saunders, J.H.B., Oliver, R.J. \& Higson, D.L. Dyspepsia: incidence of non-ulcer disease in a controlled trial of ranitidine in general practice. $\mathrm{Br}$ Med J 1986, 292: 665-668.

18. Colin-Jones, D.G. Management of dyspepsia: report of a Working Party. Lancet 1988, 1: 576-579.

19. Drossman, D.A., Thompson, G.W., Talley, N.J., FunchJensen, P., Janssens, J. \& Whitehead, W.E. Identification of sub-groups of functional gastro-intestinal disorders. Gastroenterol Int 1990, 3: 159-172.

20. Heading, R.C. More deliberations on dyspepsia. Lancet 1991, 2: $1535-1536$.

21. Tucci, A., Corinaldesi, R., Stanghellini, V., Tosetti, C., Di Febo, G., Paparo, G.F. et al. Helicobacter pylori infection and gastric function in patients with chronic idiopathic dyspepsia. Gastroenterology 1992, 103: 768-774.

22. Jones, R. \& Lydeard, S.E. Prevalence of symptoms of dyspepsia in the community. $\mathrm{Br}$ Med $J$ 1989, 298: 30-32.

23. Jones, R.H., Lydeard, S.E., Hobbs, F.D.R., Kenkre, J.E., Williams, E.I., Jones, S.J. et al. Dyspepsia in England and Scotland. Gut 1990, 31: 401-405.

24. Jones, R. \& Lydeard, S. Dyspepsia in the community: a follow-up study. Br J Clin Pract 1992, 46: 95-97.

25. Talley, N.J., Zinsmeister, A.R., Schleck, C.D. \& Melton, L.J. Dyspepsia and dyspepsia sub-groups: a population based study. Gastroenterology 1992, 102: 1259-1268. 